\title{
Burden and prevalence of risk factors for severe COVID-19 disease in the ageing European population - A SHARE-based analysis
}

Linda Juel Ahrenfeldt ( $\square$ lahrenfeldt@health.sdu.dk)

University of Southern Denmark https://orcid.org/0000-0002-5018-1642

Camilla Riis Nielsen

University of Southern Denmark https://orcid.org/0000-0003-4782-6160

Sören Möller

Odense University Hospital https://orcid.org/0000-0003-0858-4269

Kaare Christensen

University of Southern Denmark https://orcid.org/0000-0002-5429-5292

\section{Rune Lindahl-Jacobsen}

University of Southern Denmark https://orcid.org/0000-0002-4622-9826

\section{Research Article}

Keywords: COVID-19, SARS-CoV-2, prevalence, risk factors, burden of disease, Europe

Posted Date: September 9th, 2020

DOI: https://doi.org/10.21203/rs.3.rs-73657/v1

License: @ (i) This work is licensed under a Creative Commons Attribution 4.0 International License. Read Full License

Version of Record: A version of this preprint was published at Journal of Public Health on April 11th, 2021. See the published version at https://doi.org/10.1007/s10389-021-01537-7. 


\section{Abstract}

Aim: International health authorities suggest that individuals aged 65 years and above and people with underlying comorbidities such as hypertension, chronic lung disease, cardiovascular disease, cancer, diabetes, and obesity are at increased risk of severe Coronavirus Disease 2019 (COVID-19); however, the prevalence of risk factors is unknown in many countries. Therefore, we aim to describe the distribution of these risk factors across Europe.

Subject and Methods: Prevalence of risk factors for severe COVID-19 was identified based on interview for 73,274 Europeans aged 50+ participating in the Survey of Health, Ageing and Retirement in Europe (SHARE) in 2017. Burden of disease was estimated using population data from Eurostat.

Results: A total of $75.3 \%$ of the study population (corresponding to app. 60 million European men and 71 million women) had at least one risk factor for severe COVID-19, $45.9 \%$ (app. 36 million men and 43 million women) had at least two factors and 21.2\% (app. 17 million men and 20 million women) had at least three risk factors. The prevalences of underlying medical conditions ranged from $4.5 \%$ for cancer to $41.4 \%$ for hypertension, and the region-specific prevalence of having at least three risk factors ranged from $18.9 \%$ in Northern Europe to $24.6 \%$ in Eastern Europe.

Conclusions: Information about the prevalences of risk factors might help authorities to identify the most vulnerable subpopulations with multiple risk factors of severe COVID-19 disease and thus to decide appropriate strategies to mitigate the pandemic.

\section{Introduction}

During the last two decades, coronaviruses have caused major epidemics and outbreaks worldwide (Hon et al. 2020). In 2002, an epidemic of severe acute respiratory syndrome (SARS-CoV) was identified in China and spread subsequently to the rest of the world with a case-fatality of about $10 \%$ (Al-Hazmi 2016 ; Hon et al. 2020). In 2012, an epidemic of pneumonia occurred in Saudi Arabia, which was caused by another novel coronavirus called the Middle East respiratory syndrome (MERS-CoV) (Hon et al. 2020). MERS was identified in several countries in the gulf region, Korea and European region with a death rate of about 34\% (Al-Hazmi 2016; Hon et al. 2020). In the winter 2019, a new outbreak of pneumonia occurred in Wuhan, China and spread rapidly over the world. A novel coronavirus (COVID-19) was identified as the underlying cause and has been named SARS-CoV-2 due to its similarities with SARS (Hon et al. 2020). These major outbreaks of coronavirus are similar in nature and in the mode of spread by droplets (Hon et al. 2020). A review of 25 papers found that older age, male sex and underlying medical conditions including diabetes mellitus, renal disease, respiratory disease, heart disease and hypertension were clinical predictors of death associated with MERS (Matsuyama et al. 2016). Among the five predictors, the largest risk of mortality was found for heart disease (odds ratio $(O R)=3.5)$ followed by respiratory disease $(O R=3.1)$. Similarly for SARS, older age and having multiple comorbidities such as diabetes mellitus, hypertension, and cerebrovascular disease were independent predictors of various adverse outcomes such as enrollment to an intensive care unit and death (Chan et al. 2003; Lien et al. 2008).

Deaths caused by COVID-19 have by August 20, 2020 been confirmed to have passed more than 788,000 persons and 22 million persons are confirmed infected with the virus (JOHNS HOPKINS University \& Medicine 2020). Guidelines from the Center for Disease Control and Prevention (CDC) (Centers for Disease Control and Prevention 2020) and European Centre for Disease Prevention and Control (ECDC) (European Centre for Disease Prevention and Control 2020) suggest that older people and those with underlying medical conditions such as hypertension, chronic lung disease, cardiovascular disease, cancer, diabetes, and obesity are at high risk of becoming severely ill (i.e. requiring hospitalization, intensive care, ventilator treatment to help breath) or dying from COVID-19.

The risk factors are primarily based on studies from Wuhan, China showing that the most severe and fatal cases of COVID-19 have occurred in elderly people and in patients with underlying comorbidities (Guan et al. 2020a; Guan et al. 2020b; Shahid et al. 2020; Singhal 2020; Wu and McGoogan 2020; Yang et al. 2020; Zhang et al. 2020; Zheng et al. 2020; Zhou et al. 2020). Based on the available evidence, age stands out as the predominant single risk factor for severe COVID-19 disease, but it is unknown, which of the underlying medical conditions are most important for developing severe disease (National Board of Health (Denmark) 2020; Norwegian Institute of Public Health 2020). However, a large cross-sectional study from the USA (Petrilli et al. 2020) describing characteristics of 4103 patients with COVID-19 disease, found that obesity (Body Mass Index (BMI) $>30$ ) was the chronic condition with the strongest association with critical illness (Petrilli et al. 2020). In line, a retrospective analysis (Lighter et al. 2020) found that among COVID-19 patients younger than 60 years, those with a BMI of 30-34 were twice as likely to be admitted to acute and critical care than patients with a BMI of less than 30 . This was even more pronounced among patients with a BMI of 35 years and above (Lighter et al. 2020). Cardiovascular disease was a common comorbidity among people infected with SARS and MERS (Askin et al. 2020). A review of six studies including 1527 patients with COVID-19 (mainly from Wuhan) found that the most prevalent cardiovascular comorbidities were hypertension (17.1\%) and cardia-cerebrovascular disease (16.4\%) followed by diabetes (9.7\%) (Li et al. 2020) . A systematic review and meta-analyses involving 23,736 cancer patients found that cancer patients with COVID-19 had higher mortality (OR $=2.54)$, however, largely driven by mortality among patients in China (Venkatesulu et al. 2020).

A recent study identified subpopulations at risk of severe COVID-19 using national health care and population registers on the total Swedish population (about 9 million individuals) with an average age of 41.4 years (Gémes et al. 2020). They found that $22.1 \%$ of the population had at least one of six risk factors for severe COVID-19 (cardiovascular disease, cancer, chronic obstructive compulsory disease, severe asthma, diabetes and age 70+), 6.8\% had at least two factors and $1.6 \%$ had at least three risk factors. They showed that the distribution of risk factors for severe COVID-19 differed across Sweden, and highlighted that the prevalence of risk factors is unknown in many countries (Gémes et al. 2020).

Here we examine the distribution of risk factors for severe COVID-19 in middle-aged and elderly men and women aged 50 and above from 26 European countries using data from the latest available wave of the Survey of Health, Ageing and Retirement in Europe (SHARE). We aim to estimate the prevalence (proportion) and burden (raw numbers) of risk factors to describe the distribution of these risk factors throughout Europe. 


\section{Methods}

\section{Setting and study population}

SHARE is a large cross-national survey, collecting individual data about health, economic, and social factors of Europeans aged 50 and above. The SHARE data collection is done according to strict quality standards and with ex-ante harmonized interviews across the different countries (Borsch-Supan et al. 2013). To help reduce potential selection bias associated with nonresponse errors, SHARE provides calibrated weights. The calibrated cross-sectional weights in wave 7 are computed separately by country to match the size of national target populations of individuals age 50 and older in 2017 (SHARE 2020 ). To compensate for attrition, refresher respondents are added in each wave of SHARE (Borsch-Supan et al. 2013). The household response rate differ by wave and country and vary between $35.2 \%$ and $84.3 \%$ for refreshers in wave 7 (Bergmann et al. 2019).

We performed a large cross-sectional study including men and women aged 50 years and above from 26 European countries available in SHARE wave 7 (2017). We excluded individuals with unknown birth date $(n=26)$ and with missing cross-sectional individual weights $(n=173)$.

\section{Health variables}

Based on guidelines from CDC (Centers for Disease Control and Prevention 2020) and ECDC (European Centre for Disease Prevention and Control 2020), the risk factors from SHARE selected for analyses were age 65 years and above, hypertension, chronic lung disease, cardiovascular disease, cancer, diabetes, and obesity (Table 1). Disease burden was based on the following interview question: "Has a doctor ever told you that you had/do currently have any of the conditions on this card? [With this we mean that a doctor has told you that you have this condition, and that you are either currently being treated for or bothered by this condition]". The following diseases were included: "High blood pressure or hypertension", "Chronic lung disease such as chronic bronchitis or emphysema", "Heart attack including myocardial infarction or coronary thrombosis or any other heart problem including congestive heart failure", "A stroke or cerebral vascular disease", "Cancer or malignant tumor, including leukemia or lymphoma, but excluding minor skin cancers" and "Diabetes or high blood sugar". Heart attack and stroke/cerebrovascular disease were combined into one variable "Cardiovascular disease". BMI was available based on self-reported height and weight with obesity defined as a BMI of 30 and above. Number of risk factors for severe COVID-19 was estimated based on the six underlying medical conditions (including obesity) and age 65+.

\section{Sociodemographic variables}

Sociodemographic characteristics included age at interview, sex, European region and country. Age was divided into five intervals: 50-59, 60-69, 70-79, 8089 and 90+ years. In line with previous SHARE studies (Ahrenfeldt et al. 2019; Ahrenfeldt et al. 2018; Scheel-Hincke et al. 2019), the European countries were classified into four regions: Northern Europe (Denmark, Sweden and Finland), Western Europe (Austria, Germany, France, Switzerland, Belgium, and Luxembourg), Southern Europe (Spain, Italy, Greece, Portugal, Cyprus and Malta) and Eastern Europe (Czech Republic, Poland, Hungary, Slovenia, Estonia, Croatia, Lithuania, Bulgaria, Latvia, Romania, and Slovakia).

\section{Statistical analyses}

We investigated the prevalence of risk factors for severe COVID-19 among individuals in SHARE wave 7. The prevalence of each medical condition and of having at least one, two and three risk factors were estimated in relation to European regions, age and sex, and the prevalence of people aged $65+$ was estimated in relation to regions and sex. Furthermore, the prevalences of having at least one, two and three risk factors were mapped by country. As a sensitivity analysis, we investigated the prevalences of risk factors without including age as an underlying factor. All estimation of prevalences of risk factors included the individual cross-sectional probability weights given in the dataset (Borsch-Supan et al. 2013). Differences in prevalences between European regions, age and sex were investigated using logistic regressions. The burden for the risk factors in the total European population was estimated by multiplying the prevalence of risk factors in the SHARE population with the population number (assessed on January 1,2017) in the respective regions based on the Eurostat Database (Eurostat). Stata version 16.0 was used for all analyses. R version 3.6.3 was used to map the prevalences of risk factors.

\section{Results}

The mean age in the study population was 68 years (age range $50-104$ years). Among the 73,274 individuals, $43.3 \%$ were men and $56.7 \%$ were women. The study population was distributed with $11.0 \%$ in Northern Europe, 25.5\% in Western Europe, $20.7 \%$ in Southern Europe and 42.4\% in Eastern Europe (Supplementary Table 1). Among the underlying medical conditions less than one percent of data were missing except from obesity, where $3.7 \%$ were missing (not shown in table).

In total, $75.3 \%$ of the study population had at least one risk factor for severe COVID-19, $45.9 \%$ had at least two factors and $21.2 \%$ had at least three factors. Overall, the prevalences for the risk factors were similar between European regions, except for higher prevalences in Eastern Europe (Table 2 and Supplementary Table 2). Prevalences of risk factors showed only minor differences for men across the European regions, whereas women in Eastern Europe had higher prevalences of risk factors compared with women in North, West and South (Table 2 and Supplementary Table 2). No sex differences were found in the overall prevalences of having at least one, two and three risk factors in Northern, Western and Southern Europe except for a lower prevalence of at least one risk factor for women than men (74.2\% vs $76.1 \%)$ in Southern Europe. In Eastern Europe, higher prevalences of having one, two and three risk factors were found for women than for men $(79.6 \%$ vs $74.1 \%, 53.5 \%$ vs $46.2 \%$ and $26.6 \%$ vs $22.1 \%$, respectively). Overall, more women than men were 65 years and above ( $53.8 \%$ vs $47.5 \%$ ), and women had lower prevalences of lung disease ( $5.2 \%$ vs $6.1 \%)$, cardiovascular disease (12.0\% vs $16.0 \%)$ and diabetes ( $12.4 \%$ vs $14.4 \%$ ) than men (Table 2 and Supplementary Table 3). 
When mapping the prevalences of risk factors in the 26 European countries (Figure 1), we found that the prevalence of having at least one risk factor ranged from $62.4 \%$ in Slovakia to $82.7 \%$ in Hungary; having at least two factors ranged from $33.5 \%$ in Slovakia to $57.7 \%$ in Hungary; and having at least three risk factors ranged from 13.5\% in Slovakia to $29.2 \%$ in Czech Republic (Figure 1). For women, the highest prevalences of risk factors were found in Eastern Europe, with Hungary (83.5\%), Lithuania (83.1\%) and Latvia (82.8\%) having the highest prevalences of at least one risk factor, and Lithuania (59.0\% and $31.1 \%$ ), Estonia (55.6\% and $28.5 \%$ ) and Latvia (55.0\% and $30.1 \%$ ) having the highest prevalences of at least two and three risk factors, respectively. For men, a less consistent pattern was found. The highest prevalences of having at least one risk factor were found in Portugal (86.8\%), Malta (86.6\%) and Czech Republic (83.1\%), the highest prevalences of having at least two factors were found in Czech Republic (59.8\%), Hungary (52.8\%) and Malta (51.0\%) followed by Spain (50.7\%) and Finland (50.1\%), and the highest prevalences of having at least three factors were found in Czech Republic (31.8\%), Hungary (26.0\%) and Malta (25.4\%) (Figure 1 and Supplementary Table 4).

The overall prevalence of the underlying medical conditions in the total sample was $41.4 \%$ for hypertension, $5.6 \%$ for chronic lung disease, $13.8 \%$ for cardiovascular disease, $4.5 \%$ for cancer, $13.3 \%$ for diabetes and $21.4 \%$ for obesity, but varied between European regions (Table 2). The most pronounced differences between regions were found for Eastern Europe. Compared with Northern and Western Europe, Eastern Europe had higher prevalences of hypertension, cardiovascular disease, diabetes and obesity, but lower prevalences of lung disease and cancer. Compared with Southern Europe, Eastern Europe had higher prevalences of hypertension, cardiovascular disease and obesity (Table 2 and Supplementary Table 2).

Overall, the prevalences of having at least one, two and three risk factors increased with age until the age group 80-89 years but decreased thereafter. Also, the prevalence of each medical condition generally increased with age; however, the prevalences of obesity increased until age 60-69 years, were overall stable until age 80-89 years, and decreased thereafter (Table 2 and Supplementary Table 5).

When estimating the prevalences of risk factors without age as an underlying factor, the overall prevalences of having at least one, two and three risk factors decreased to $60.3 \%, 27.9 \%$ and $9.5 \%$, respectively (Supplementary Table 6).

Given the prevalences found in the SHARE population, we estimated that the number of individuals having at least one of the risk factors for severe COVID-19 in the European population was about 131 million persons (70,672,673 women and 60,104,205 men). Almost 80 million persons ( $42,592,064$ women and $36,253,330$ men) had at least two risk factors and almost 37 million persons (20,165,269 women and 16,695,613 men) had at least three risk factors (Table 3). The burden of the underlying medical conditions ranged from about 8 million persons with cancer to about 72 million persons with hypertension. The region-specific burden of having at least three risk factors ranged from 1.5 million persons in Northern Europe to 9.5 million persons in Eastern Europe (Table 3). The burden of risk factors in the specific age groups can be found in Supplementary Table 7.

\section{Discussion}

Using data from SHARE wave 7, we found that the main part of the study population aged 50+ years (about $75 \%$ corresponding to app. 60 million European men and 71 million women) had at least one risk factor for severe COVID-19, 46\% (app. 36 million men and 43 million women) had at least two factors and $21 \%$ (app. 17 million men and 20 million women) had at least three risk factors. The prevalence of underlying medical conditions ranged from $4.5 \%$ for cancer to $41.4 \%$ for hypertension. Overall, the prevalences of risk factors increased with age until 80-89 years. Generally, the prevalences were similar between the European regions, except for higher prevalences of risk factors in Eastern Europe, mainly explained by a higher prevalence for women in Eastern Europe compared with women in Northern, Western and Southern Europe.

Compared with the recent study identifying subpopulations at risk of severe COVID-19 in Sweden (Gémes et al. 2020), we found higher prevalences of risk factors. This is at least partly explained by the differences in average age in the two study populations (41 vs 68 years) and the different ways information was gathered. The Swedish data was based on hospitalizations, representing those with most severe disease, with diagnoses of medical conditions within three years prior to January 1, 2016 to capture individuals with active disease. Our study was based on self-reported conditions. Thus, we capture both individuals with active disease, but also persons who had the specific disease back in time. In line, the Swedish study found an overall greater burden of risk factors as the look back period increased (Gémes et al. 2020).

In line with the regional differences observed in this study, other SHARE-studies demonstrated the highest prevalence of disability in Eastern and Southern Europe (Scheel-Hincke et al. 2019) and the lowest physical strength in Eastern Europe (Ahrenfeldt et al. 2018). Another recent study found that Eastern Europe had the highest proportion of individuals with a comorbidity index of two or more, and that women had more comorbidity than men in Eastern, Southern, and Northern Europe, but most pronounced in Eastern Europe (Ahrenfeldt et al. 2019).

In agreement with observations in this study showing overall similar prevalences of risk factors between men and women, available sex-disaggregated data for COVID-19 show equal numbers of cases between sexes (Spagnolo et al. 2020). However, men with COVID-19 are more at risk for worse outcomes and death, independent of age (Jin et al. 2020). Plausible reasons for this sex difference include high risk behaviors, immune response, biological differences between the sexes and the contribution of underlying cardiovascular risk factors, which is higher among men than among women (Sharma et al. 2020).

To prevent severe disease of COVID-19, it is important for national and international authorities and local governments to identify the possible subpopulations with increased risk. Current evidence on COVID-19 from China found that the hazard ratio of reaching the composite endpoint (i.e. admission to an intensive care unit, invasive ventilation or death) was 1.79 for patients with at least one comorbidity and 2.59 for patients with two or more comorbidities (Guan et al. 2020a). In agreement with global estimates (Clark et al. 2020), results from the present study show that large parts of the middle-aged and elderly populations will have at least one risk factor for severe COVID-19 making interventions towards all persons with risk factors infeasible; nevertheless, identifying the most vulnerable subpopulations with multiple risk factors, shown here to be about one fifth of the European population, may help authorities in planning healthcare resources and to decide appropriate strategies to mitigate the pandemic and reduce mortality from the disease (Gémes et al. 2020).

Page $4 / 10$ 
The main strength of this study is the large national samples of participants from 26 European countries with harmonized disease measures (Borsch-Supan et al. 2013), making it possible to visualize the prevalence and burden of risk factors for severe COVID-19 by European regions and countries. Although we used the latest wave of SHARE, the present study was based on data from 2017. Thus, if the structure of the European population has changed during the last three years, the prevalence estimates may be different now. The medical conditions included in the analysis are all some of the most prevalent underlying conditions observed among COVID-19 cases with severe disease according to ECDC (European Centre for Disease Prevention and Control 2020) and CDC (Centers for Disease Control and Prevention 2020). However, still a lot is unknown about the number and the impact of risk factors on COVID-19 and there might be more relevant risk factors than the ones considered here. While the World Health Organization (WHO) also list a number of underlying medical conditions associated with high risk of developing serious COVID-19 illness, they do not define what "serious illness" entails, and thus we have not referred to WHO in this paper. Nevertheless, many of the risk factors mentioned by WHO is the same as mentioned by ECDC and CDC (World Health Organization 2020). Limitations to the SHARE data are that the sampling procedures might vary by country and the low response rate in some countries. However, to try to correct for potential selection into the study population, SHARE provides calibrated probability weights, which are constructed to reduce the impact of both unit and item nonresponse (Borsch-Supan et al. 2013; SHARE 2020). Moreover, misclassification is an issue because diseases are self-reported; however, by using selfreported data in contrast to register-based hospitalization data, we were able to calculate the prevalences of risk factors of COVID-19 among the general European population, and not only among people with most severe disease requiring hospital admission.

This is to our knowledge the largest study to date based on individual level data describing the prevalence and burden of risk factors for COVID-19 across European regions. About $75 \%$ of the study population (corresponding to app. 60 million European men and 71 million women) had at least one risk factor for COVID-19, whereas about 21\% (app. 17 million men and 20 million women) had at least three risk factors. The prevalence of the underlying medical conditions ranged from $4.5 \%$ for cancer to $41.4 \%$ for hypertension. Generally, the prevalences were similar between the European regions, except for higher prevalences of risk factors in Eastern Europe particularly among women. Information about the prevalences of risk factors might help authorities to identify the most vulnerable subpopulations with multiple risk factors of severe COVID-19 disease and thus to decide appropriate strategies to mitigate the pandemic.

\section{Declarations}

This study was part of the Survey of Health, Ageing and Retirement in Europe (SHARE). The SHARE study is under continuous ethics review. Waves $1-4$ were approved by the Ethics Committee of the University of Mannheim. Wave 4 and onwards were approved by the Ethics Council of the Max Planck Society for the Advancement of Science (MPG). Further information can be found on the SHARE webpage (www.share-project.org). Written informed consent was obtained from all participants included in the study.

\section{Funding}

This study was supported by research Grants from Demography of Sex Differences in Health and Survival P01 AG031719.

\section{Acknowledgment}

This paper uses data from SHARE Wave 7 (DOls: 10.6103/SHARE.w7.700); see Börsch-Supan et al. (2013) for methodological details (Borsch-Supan et al. 2013). The SHARE data collection has been primarily funded by the European Commission through FP5 (QLK6-CT-2001-00360), FP6 (SHARE-I3: RII-CT-2006062193, COMPARE: CIT5-CT2005-028857, SHARELIFE: CIT4-CT-2006-028812) and FP7 (SHARE-PREP: №211909, SHARE-LEAP: N²27822, SHARE M4: $N^{\circ}$ 261982). Additional funding from the German Ministry of Education and Research, the Max Planck Society for the Advancement of Science, the U.S. National Institute on Aging (U01_AG09740-13S2, P01_AG005842, P01_AG08291, P30_AG12815, R21_AG025169, Y1-AG-4553-01, IAG_BSR06-11, OGHA_04064, HHSN271201300071C) and from various national funding sources is gratefully acknowledged (see www.share-project.org).

\section{Conflicts of interest}

The authors declare that they have no conflicts of interest.

\section{References}

1. Ahrenfeldt LJ, Moller S, Thinggaard M, Christensen K, Lindahl-Jacobsen R (2019) Sex Differences in Comorbidity and Frailty in Europe International journal of public health 64:1025-1036 doi:10.1007/s00038-019-01270-9

2. Ahrenfeldt LJ, Scheel-Hincke LL, Kjaergaard S, Moller S, Christensen K, Lindahl-Jacobsen R (2018) Gender differences in cognitive function and grip strength: a cross-national comparison of four European regions Eur J Public Health doi:10.1093/eurpub/cky266

3. Al-Hazmi A (2016) Challenges presented by MERS corona virus, and SARS corona virus to global health Saudi J Biol Sci 23:507-511 doi:10.1016/j.sjbs.2016.02.019

4. Askin L, Tanriverdi O, Askin HS (2020) The Effect of Coronavirus Disease 2019 on Cardiovascular Diseases Arq Bras Cardiol 114:817-822 doi:10.36660/abc.20200273

5. Bergmann M, Kneip T, Luca GD, Scherpenzeel A (2019) Survey participation in the Survey of Health, Ageing and Retirement in Europe (SHARE), Wave 1-7. Based on Release 7.0.0.

6. Borsch-Supan A et al. (2013) Data Resource Profile: the Survey of Health, Ageing and Retirement in Europe (SHARE) Int J Epidemiol 42:992-1001 doi:10.1093/ije/dyt088

7. Centers for Disease Control and Prevention (2020) Coronavirus Disease 2019 (COVID-19). https://www.cdc.gov/coronavirus/2019-ncov/need-extraprecautions/people-at-higher-risk.html. Accessed August 20, 2020

Page 5/10 
8. Chan KS, Zheng JP, Mok YW, Li YM, Liu YN, Chu CM, Ip MS (2003) SARS: prognosis, outcome and sequelae Respirology (Carlton, Vic) 8 Suppl:S36-S40 doi:10.1046/j.1440-1843.2003.00522.x

9. Clark A et al. (2020) Global, regional, and national estimates of the population at increased risk of severe COVID-19 due to underlying health conditions in 2020: a modelling study Lancet Glob Health doi:10.1016/s2214-109x(20)30264-3

10. European Centre for Disease Prevention and Control (2020) Disease background of COVID-19. https://www.ecdc.europa.eu/en/2019-ncov-backgrounddisease. Accessed August 20, 2020

11. Eurostat Eurostat database. Eurostat. http://ec.europa.eu/eurostat/data/database. May 1, 2020

12. Gémes K, Talbäck M, Modig K, Ahlbom A, Berglund A, Feychting M, Matthews AA (2020) Burden and prevalence of prognostic factors for severe CoVID-19 in Sweden Eur J Epidemiol 35:401-409 doi:10.1007/s10654-020-00646-z

13. Guan WJ et al. (2020a) Comorbidity and its impact on 1590 patients with COVID-19 in China: a nationwide analysis Eur Respir J 55 doi:10.1183/13993003.00547-2020

14. Guan WJ et al. (2020b) Clinical Characteristics of Coronavirus Disease 2019 in China N Engl J Med 382:1708-1720 doi:10.1056/NEJMoa2002032

15. Hon KL, Leung KKY, Leung AKC, Sridhar S, Qian S, Lee SL, Colin AA (2020) Overview: The history and pediatric perspectives of severe acute respiratory syndromes: Novel or just like SARS Pediatr Pulmonol doi:10.1002/ppul.24810

16. Jin JM et al. (2020) Gender Differences in Patients With COVID-19: Focus on Severity and Mortality Front Public Health 8:152 doi:10.3389/fpubh.2020.00152

17. JOHNS HOPKINS University \& Medicine (2020) Coronavirus Resource Center, . https://coronavirus.jhu.edu/map.html. Accessed August 20, 2020

18. Li B et al. (2020) Prevalence and impact of cardiovascular metabolic diseases on COVID-19 in China Clin Res Cardiol 109:531-538 doi:10.1007/s00392020-01626-9

19. Lien TC et al. (2008) Characteristic features and outcomes of severe acute respiratory syndrome found in severe acute respiratory syndrome intensive care unit patients J Crit Care 23:557-564 doi:10.1016/j.jcrc.2007.05.004

20. Lighter J, Phillips M, Hochman S, Sterling S, Johnson D, Francois F, Stachel A (2020) Obesity in Patients Younger Than 60 Years Is a Risk Factor for COVID-19 Hospital Admission Clin Infect Dis doi:10.1093/cid/ciaa415

21. Matsuyama R, Nishiura H, Kutsuna S, Hayakawa K, Ohmagari N (2016) Clinical determinants of the severity of Middle East respiratory syndrome (MERS): a systematic review and meta-analysis BMC Public Health 16:1203 doi:10.1186/s12889-016-3881-4

22. National Board of Health (Denmark) (2020) Personer med øget risiko ved COVID-19. Fagligt grundlag.

23. Norwegian Institute of Public Health (2020) COVID-19: The relationship between age, comorbidity and disease severity - a rapid review, 1. Update April 2020. .

24. Petrilli CM et al. (2020) Factors associated with hospitalization and critical illness among 4,103 patients with COVID-19 disease in New York City medRxiv:2020.2004.2008.20057794 doi:10.1101/2020.04.08.20057794

25. Scheel-Hincke LL, Möller S, Lindahl-Jacobsen R, Jeune B, Ahrenfeldt LJ (2019) Cross-national comparison of sex differences in ADL and IADL in Europe: findings from SHARE European Journal of Ageing:1-11 doi:10.1007/s10433-019-00524-y

26. Shahid Z et al. (2020) COVID-19 and Older Adults: What We Know J Am Geriatr Soc 68:926-929 doi:10.1111/jgs.16472

27. SHARE (2020) Survey of Health, Ageing and Retirement in Europe. Release guide 7.1.0.

28. Sharma G, Volgman AS, Michos ED (2020) Sex Differences in Mortality from COVID-19 Pandemic: Are Men Vulnerable and Women Protected? JACC Case Rep doi:10.1016/j.jaccas.2020.04.027

29. Singhal T (2020) A Review of Coronavirus Disease-2019 (COVID-19) Indian J Pediatr 87:281-286 doi:10.1007/s12098-020-03263-6

30. Spagnolo PA, Manson JE, Joffe H (2020) Sex and Gender Differences in Health: What the COVID-19 Pandemic Can Teach Us Ann Intern Med doi:10.7326/m20-1941

31. Venkatesulu BP et al. (2020) A systematic review and meta-analysis of cancer patients affected by a novel coronavirus medRxiv doi:10.1101/2020.05.27.20115303

32. World Health Organization (2020) Q\&A: Older people and COVID-19. https://www.who.int/emergencies/diseases/novel-coronavirus-2019/question-andanswers-hub/q-a-detail/q-a-on-on-covid-19-for-older-people. Accessed August 20, 2020

33. Wu Z, McGoogan JM (2020) Characteristics of and Important Lessons From the Coronavirus Disease 2019 (COVID-19) Outbreak in China: Summary of a Report of 72314 Cases From the Chinese Center for Disease Control and Prevention JAMA 323:1239-1242 doi:10.1001/jama.2020.2648

34. Yang X et al. (2020) Clinical course and outcomes of critically ill patients with SARS-CoV-2 pneumonia in Wuhan, China: a single-centered, retrospective, observational study Lancet Respir Med 8:475-481 doi:10.1016/s2213-2600(20)30079-5

35. Zhang JJ et al. (2020) Clinical characteristics of 140 patients infected with SARS-CoV-2 in Wuhan, China Allergy doi:10.1111/all.14238

36. Zheng Z et al. (2020) Risk factors of critical \& mortal COVID-19 cases: A systematic literature review and meta-analysis J Infect doi:10.1016/j.jinf.2020.04.021

37. Zhou F et al. (2020) Clinical course and risk factors for mortality of adult inpatients with COVID-19 in Wuhan, China: a retrospective cohort study Lancet 395:1054-1062 doi:10.1016/s0140-6736(20)30566-3

\section{Tables}

Page 6/10 
Table 1 - Identified risk factors for severe COVID-19 by the Center for Disease Control and Prevention (CDC) and European Centre for Disease Prevention and Control (ECDC), and data selected for the present study from the Survey of Health, Ageing and Retirement in Europe (SHARE)

\begin{tabular}{|c|c|c|}
\hline $\mathrm{CDC}^{\mathrm{a}}$ & $E C D C^{b}$ & $\begin{array}{l}\text { Risk factors from SHARE selected for the present } \\
\text { study }\end{array}$ \\
\hline \multirow[t]{2}{*}{65 years and above } & $\begin{array}{l}70 \text { years and } \\
\text { above }\end{array}$ & 65 years and above \\
\hline & Hypertension & High blood pressure or hypertension \\
\hline People with diabetes & Diabetes & Diabetes or high blood sugar \\
\hline \multirow[t]{2}{*}{ People who have serious heart conditions } & \multirow{2}{*}{$\begin{array}{l}\text { Cardiovascular } \\
\text { Diseases }\end{array}$} & Cardiovascular Disease \\
\hline & & $\begin{array}{l}\text { (Heart attack including myocardial infarction or } \\
\text { coronary thrombosis or any other heart problem } \\
\text { including congestive heart failure and stroke or } \\
\text { cerebral vascular disease) }\end{array}$ \\
\hline \multirow[t]{2}{*}{ People with chronic lung disease or moderate to severe asthma } & $\begin{array}{l}\text { Chronic } \\
\text { Respiratory } \\
\text { Diseases }\end{array}$ & $\begin{array}{l}\text { Chronic lung disease such as chronic bronchitis or } \\
\text { emphysema }\end{array}$ \\
\hline & Cancer & $\begin{array}{l}\text { Cancer or malignant tumor including leukemia or } \\
\text { lymphoma excluding minor skin cancers }\end{array}$ \\
\hline People with severe obesity (BMI 40+) & $\begin{array}{l}\text { Obesity (BMI } \\
30-40+)\end{array}$ & $\mathrm{BMI}=30+$ \\
\hline \multicolumn{3}{|l|}{ People with liver disease } \\
\hline \multicolumn{3}{|l|}{ People with chronic kidney disease undergoing dialysis } \\
\hline \multicolumn{3}{|l|}{ People who live in a nursing home or long-term care facility } \\
\hline $\begin{array}{l}\text { People who are immunocompromised (cancer treatment, smoking, bone marrow } \\
\text { or organ transplantation, immune deficiencies, poorly controlled HIV or AIDS, and } \\
\text { prolonged use of corticosteroids and other immune weakening medications) }\end{array}$ & $\begin{array}{l}\text { Immune } \\
\text { compromised } \\
\text { status }\end{array}$ & \\
\hline
\end{tabular}

Accessed August 20, 2020

${ }^{a}$ Centers for Disease Control and Prevention. Coronavirus Disease 2019 (COVID-19). https://www.cdc.gov/coronavirus/2019-ncov/need-extraprecautions/people-at-higher-risk.html

${ }^{b}$ European Centre for Disease Prevention and Control. Disease background of COVID-19. 2020. https://www.ecdc.europa.eu/en/2019-ncov-backgrounddisease

Table 2 - Prevalence of risk factors for COVID-19 by European region and age group for the total population and stratified by sex 


\begin{tabular}{|c|c|c|c|c|c|c|c|c|c|c|}
\hline & $\begin{array}{l}\text { Age } 65 \\
\text { and } \\
\text { above }\end{array}$ & Hypertension & $\begin{array}{l}\text { Chronic } \\
\text { lung } \\
\text { disease }\end{array}$ & $\begin{array}{l}\text { Cardiovascular } \\
\text { disease }\end{array}$ & Cancer & Diabetes & Obesity & $\begin{array}{l}\text { At least one } \\
\text { prognos-tic } \\
\text { factor }\end{array}$ & $\begin{array}{l}\text { At least two } \\
\text { prognos-tic } \\
\text { factors }\end{array}$ & $\begin{array}{l}\text { At least three } \\
\text { prognos-tic } \\
\text { factors }\end{array}$ \\
\hline \multicolumn{11}{|c|}{$\begin{array}{l}\text { All } \\
\text { countries }\end{array}$} \\
\hline Total & 51.0 & 41.4 & 5.6 & 13.8 & 4.5 & 13.3 & 21.4 & 75.3 & 45.9 & 21.2 \\
\hline Men & $47.7^{\mathrm{a}}$ & 40.8 & $6.1^{\mathrm{a}}$ & $16.0^{\mathrm{a}}$ & 4.6 & $14.4^{\mathrm{a}}$ & 21.5 & 75.6 & 45.6 & 21.0 \\
\hline Women & 53.8 & 41.9 & 5.2 & 12.0 & 4.5 & 12.4 & 21.4 & 75.0 & 45.2 & 21.4 \\
\hline \multicolumn{11}{|l|}{$\begin{array}{l}\text { Northern } \\
\text { EU }\end{array}$} \\
\hline Total & 52.5 & 38.1 & 6.0 & 12.5 & 5.6 & 11.1 & 19.5 & 74.3 & 43.3 & 18.9 \\
\hline Men & $50.5^{a}$ & 38.6 & 5.6 & $14.5^{\mathrm{a}}$ & 5.5 & $13.5^{\mathrm{a}}$ & 19.2 & 74.9 & 44.7 & 19.0 \\
\hline Women & 54.3 & 37.6 & 6.3 & 10.7 & 5.6 & 8.9 & 19.7 & 73.7 & 42.1 & 18.9 \\
\hline \multicolumn{11}{|l|}{$\begin{array}{l}\text { Western } \\
\text { EU }\end{array}$} \\
\hline Total & 50.6 & 39.0 & 6.6 & 14.1 & 5.8 & 12.3 & 21.8 & 75.1 & 45.1 & 20.3 \\
\hline Men & $47.4^{a}$ & 39.8 & 6.6 & $17.1^{\mathrm{a}}$ & 5.9 & $14.3^{a}$ & 22.7 & 76.2 & 45.9 & 21.1 \\
\hline Women & 53.4 & 38.2 & 6.6 & 11.5 & 5.6 & 10.6 & 21.1 & 74.2 & 44.4 & 19.7 \\
\hline \multicolumn{11}{|l|}{$\begin{array}{l}\text { Southern } \\
\text { EU }\end{array}$} \\
\hline Total & 52.8 & 41.6 & 4.9 & 11.8 & 3.3 & 14.6 & 18.9 & 74.2 & 44.3 & 20.2 \\
\hline Men & $50.1^{a}$ & 42.8 & $6.5^{a}$ & $13.9^{a}$ & 3.3 & $15.8^{a}$ & 21.8 & $76.1^{a}$ & 45.0 & 20.5 \\
\hline Women & 55.1 & 40.6 & 3.5 & 10.1 & 3.4 & 13.7 & 17.3 & 72.7 & 43.7 & 20.0 \\
\hline \multicolumn{11}{|l|}{$\begin{array}{l}\text { Eastern } \\
\text { EU }\end{array}$} \\
\hline Total & 49.0 & 47.7 & 4.9 & 16.4 & 3.8 & 14.3 & 29.1 & 77.2 & 50.3 & 24.6 \\
\hline Men & $44.3^{a}$ & $42.0^{a}$ & 5.1 & 17.2 & 3.7 & 13.5 & 18.2 & $74.1^{\mathrm{a}}$ & $46.2^{a}$ & $22.1^{\mathrm{a}}$ \\
\hline Women & 52.6 & 52.2 & 4.7 & 15.9 & 3.9 & 14.8 & 27.8 & 79.6 & 53.5 & 26.6 \\
\hline \multicolumn{11}{|l|}{$\begin{array}{l}\text { Age 50- } \\
59\end{array}$} \\
\hline Total & - & 28.8 & 4.3 & 6.4 & 3.1 & 8.1 & 21.6 & 46.7 & 17.7 & 5.7 \\
\hline Men & - & $32.0^{a}$ & $5.3^{a}$ & $8.9^{a}$ & 2.5 & $9.6^{a}$ & 22.8 & $51.5^{\mathrm{a}}$ & $20.1^{\mathrm{a}}$ & $7.0^{\mathrm{a}}$ \\
\hline Women & - & 25.7 & 3.3 & 4.0 & 3.6 & 6.6 & 20.5 & 42.1 & 15.4 & 4.4 \\
\hline \multicolumn{11}{|l|}{$\begin{array}{l}\text { Age 60- } \\
69\end{array}$} \\
\hline Total & - & 41.6 & 5.2 & 11.4 & 4.4 & 13.0 & 25.0 & 77.2 & 44.2 & 19.3 \\
\hline Men & - & 42.1 & 5.1 & $14.5^{\mathrm{a}}$ & 4.0 & $14.9^{a}$ & 25.0 & $78.3^{a}$ & $46.1^{a}$ & $20.5^{a}$ \\
\hline Women & - & 41.1 & 5.3 & 8.6 & 4.8 & 11.3 & 25.0 & 76.2 & 42.5 & 18.2 \\
\hline \multicolumn{11}{|l|}{$\begin{array}{l}\text { Age } 70- \\
79\end{array}$} \\
\hline Total & - & 53.0 & 6.8 & 19.5 & 6.4 & 18.5 & 21.2 & 100 & 71.8 & 36.0 \\
\hline Men & - & $50.3^{a}$ & 7.2 & $22.9^{a}$ & $7.7^{a}$ & $20.6^{a}$ & $18.9^{a}$ & 100 & 72.9 & 36.9 \\
\hline Women & - & 55.1 & 6.5 & 16.9 & 5.4 & 16.9 & 23.0 & 100 & 70.9 & 35.3 \\
\hline
\end{tabular}




\begin{tabular}{|c|c|c|c|c|c|c|c|c|c|c|}
\hline Total & - & 56.1 & 8.2 & 27.2 & 5.6 & 19.2 & 19.8 & 100 & 77.2 & 40.1 \\
\hline Men & - & $51.8^{a}$ & $10.2^{a}$ & $30.0^{a}$ & $7.7^{a}$ & 18.5 & $17.1^{a}$ & 100 & 76.8 & 39.2 \\
\hline Women & - & 58.6 & 6.9 & 25.5 & 4.4 & 19.6 & 21.4 & 100 & 77.4 & 40.6 \\
\hline \multicolumn{11}{|l|}{ Age 90+ } \\
\hline Total & - & 47.4 & 7.5 & 28.5 & 5.7 & 17.3 & 8.7 & 100 & 68.2 & 31.7 \\
\hline Men & - & 41.4 & 10.0 & 27.2 & 5.2 & 17.6 & 5.9 & 100 & 63.4 & 29.1 \\
\hline Women & - & 49.9 & 6.5 & 29.0 & 6.0 & 17.1 & 10.0 & 100 & 70.2 & 32.8 \\
\hline
\end{tabular}

a Significant sex difference $(p<0.05)$

Northern Europe: Sweden, Denmark and Finland

Western Europe: Austria, Germany, France, Switzerland, Belgium and Luxembourg

Southern Europe: Spain, Italy, Greece, Portugal, Malta and Cyprus

Eastern Europe: Czech Republic, Poland, Hungary, Slovenia, Estonia, Croatia, Lithuania, Bulgaria, Latvia, Romania and Slovakia

Table 3- Burden (raw numbers) of risk factors for Covid-19 by European regions

\begin{tabular}{|c|c|c|c|c|c|c|c|c|c|c|}
\hline & Age 65+ & Hypertension & $\begin{array}{l}\text { Chronic } \\
\text { lung } \\
\text { disease }\end{array}$ & $\begin{array}{l}\text { Cardiovascu- } \\
\text { lar disease }\end{array}$ & Cancer & Diabetes & Obesity & $\begin{array}{l}\text { At least one } \\
\text { risk factor }\end{array}$ & $\begin{array}{l}\text { At least } \\
\text { two risk } \\
\text { factors }\end{array}$ & $\begin{array}{l}\text { At least } \\
\text { three risk } \\
\text { factors }\end{array}$ \\
\hline \multicolumn{11}{|l|}{$\begin{array}{l}\text { All } \\
\text { countries }\end{array}$} \\
\hline Total & $85,293,598$ & $71,925,523$ & $9,729,056$ & $23,975,174$ & $7,817,992$ & $23,106,509$ & $37,178,894$ & $130,821,060$ & $79,743,515$ & $36,831,42^{-}$ \\
\hline Men & $36,259,364$ & $32,437,190$ & $4,849,678$ & $12,720,467$ & $3,657,134$ & $11,448,420$ & $17,093,127$ & $60,104,205$ & $36,253,330$ & $16,695,61:$ \\
\hline Women & $49,034,234$ & $39,482,467$ & $4,899,972$ & $11,307,628$ & $4,240,360$ & $11,684,549$ & $20,165,269$ & $70,672,673$ & $42,592,064$ & $20,165,26$ \\
\hline \multicolumn{11}{|l|}{$\begin{array}{l}\text { Northern } \\
\text { EU }\end{array}$} \\
\hline Total & $4,222,004$ & $3,148,568$ & 495,837 & $1,032,995$ & 462,782 & 917,299 & $1,611,472$ & $6,140,120$ & $3,578,293$ & $1,561,888$ \\
\hline Men & $1,914,850$ & $1,520,280$ & 220,559 & 571,090 & 216,620 & 531,704 & 756,201 & $2,949,973$ & $1,760,531$ & 748,324 \\
\hline Women & $2,307,154$ & $1,626,353$ & 272,501 & 462,819 & 242,223 & 384,961 & 852,105 & $3,187,826$ & $1,820,997$ & 817,502 \\
\hline \multicolumn{11}{|l|}{$\begin{array}{l}\text { Western } \\
\text { EU }\end{array}$} \\
\hline Total & $18,278,979$ & $28,474,960$ & $4,818,839$ & $10,294,793$ & $4,234,738$ & $8,980,564$ & $15,916,773$ & $54,832,552$ & $32,928,736$ & $14,821,58$ \\
\hline Men & $7,189,170$ & $13,474,951$ & $2,234,540$ & $5,789,489$ & $1,997,543$ & $4,841,503$ & $7,685,462$ & $25,798,776$ & $15,540,207$ & $7,143,755$ \\
\hline Women & $11,089,809$ & $14,957,614$ & $2,584,300$ & $4,502,947$ & $2,192,739$ & $4,150,542$ & $8,261,928$ & $29,053,795$ & $17,385,290$ & $7,713,743$ \\
\hline \multicolumn{11}{|l|}{$\begin{array}{l}\text { Southern } \\
\text { EU }\end{array}$} \\
\hline Total & $27,067,173$ & $22,305,719$ & $2,627,356$ & $6,327,103$ & $1,769,444$ & $7,828,449$ & $9,758,752$ & $39,785,682$ & $23,753,446$ & $10,831,14$ \\
\hline Men & $11,697,857$ & $10,539,366$ & $1,600,605$ & $3,422,831$ & 812,615 & $3,890,701$ & $4,260,071$ & $18,739,387$ & $11,081,109$ & $5,048,061$ \\
\hline Women & $15,369,316$ & $11,771,901$ & $1,014,819$ & $2,928,478$ & 985,824 & $3,972,292$ & $5,480,023$ & $21,079,241$ & $12,670,741$ & $5,798,966$ \\
\hline \multicolumn{11}{|l|}{$\begin{array}{l}\text { Eastern } \\
\text { EU }\end{array}$} \\
\hline Total & $35,725,442$ & $18,525,228$ & $1,903,011$ & $6,369,261$ & $1,475,804$ & $5,553,685$ & $11,107,369$ & $29,982,129$ & $19,534,988$ & $9,553,891$ \\
\hline Men & $15,457,487$ & $7,174,868$ & 871,234 & $2,938,279$ & 632,072 & $2,306,208$ & $4,749,080$ & $12,658,518$ & $7,892,355$ & $3,775,347$ \\
\hline Women & $20,267,955$ & $11,355,554$ & $1,022,435$ & $3,458,876$ & 848,403 & $3,219,582$ & $6,330,395$ & $17,316,132$ & $11,638,355$ & $5,786,547$ \\
\hline
\end{tabular}


Data was estimated by multiplying the prevalence of risk factors in the SHARE population (Table 2) with the population number (assessed on January 1 , 2017) in the respective countries based on the Eurostat Database

Northern Europe: Sweden, Denmark and Finland

Western Europe: Austria, Germany, France, Switzerland, Belgium and Luxembourg

Southern Europe: Spain, Italy, Greece, Portugal, Malta and Cyprus

Eastern Europe: Czech Republic, Poland, Hungary, Slovenia, Estonia, Croatia, Lithuania, Bulgaria, Latvia, Romania and Slovakia

\section{Figures}

Total
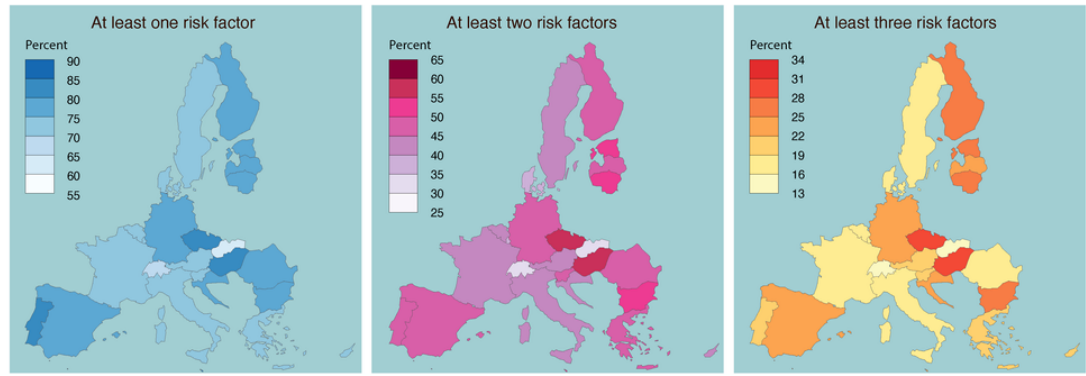

Men
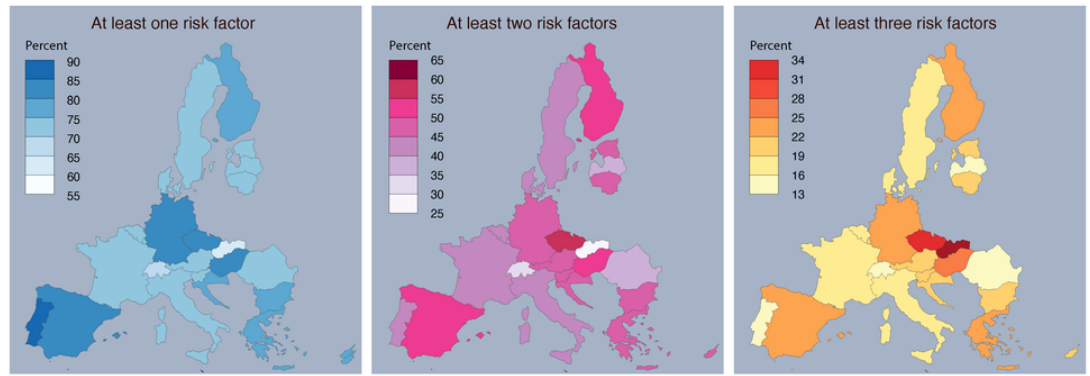

Women
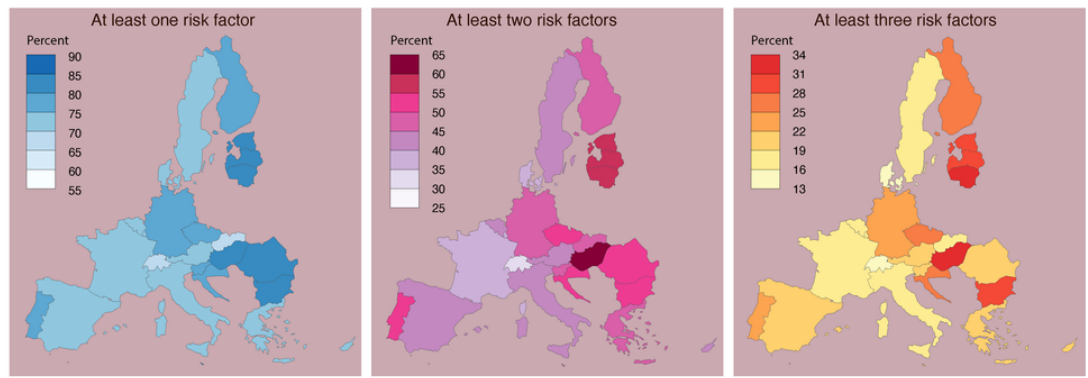

Figure 1

Maps demonstrating the prevalence of at least one, two and three risk factors for severe COVID-19 by European countries and sex.

\section{Supplementary Files}

This is a list of supplementary files associated with this preprint. Click to download.

- SuppTables.docx 